\title{
Impedimetric and electrochemical evaluation of a new redox active steroid derivative for hormone immunosensing
}

\author{
Jessica Kelch $^{\mathrm{a}}$, Aoife Delaney ${ }^{\mathrm{a}}$, Fintan Kelleher ${ }^{\mathrm{b}}$, Priscilla Baker ${ }^{\mathrm{c}}$, Emmanuel Iwuoha $^{\mathrm{c}}$, \\ Eithne Dempsey ${ }^{\text {d,"* }}$ \\ ${ }^{a}$ Centre of Applied Science for Health, Technological University Dublin, Tallaght Campus, Dublin 24, Ireland \\ ${ }^{\mathrm{b}}$ Molecular Design and Synthesis Group, Centre for Applied Science for Health, Technological University Dublin, Tallaght Campus, Dublin 24, Ireland \\ ${ }^{c}$ SensorLab, Department of Chemistry, University of the Western Cape, Private Bag X17, Bellville, 7535, South Africa \\ ${ }^{\mathrm{d}}$ Department of Chemistry, Maynooth University, Maynooth, Co. Kildare, Ireland
}

\section{A R T I C L E I N F O}

\section{Keywords:}

Electrochemical impedance spectroscopy

Progesterone thiosemicarbazone

Progesterone immunoassay

\begin{abstract}
A B S T R A C T
Preparation and electrochemical interrogation of a novel redox active progesterone derivative progesterone thiosemicarbazone (PATC) is presented here together with an investigation into its suitability as conjugate in progesterone hormone immunosensing. PATC synthesis involved a condensation reaction between progesterone acetate and thiosemicarbazone hydrochloride. Voltammetric and pulse techniques confirmed the redox behaviour of the new compound with concentration and scan rate dependant irreversible behaviour evident at glassy carbon and gold transducers $-\mathrm{k}^{\mathrm{o}}$ (standard heterogeneous rate constant) was $2.56 \times 10^{-3} \mathrm{~cm}^{2} / \mathrm{s}(\mathrm{V}=100 \mathrm{mV} / \mathrm{s} \mathrm{in}$ non-aqeuous media). Bioaffinity studies towards anti-progesterone antibodies involved a competitive ELISA format (optical) which confirmed recognition of the new progesterone derivative. Electrochemical impedance spectroscopy was employed as an interrogation technique in order to establish optimum binding and surface conditions for progesterone antigen-antibody interaction with the assistance of a redox probe (potassium hexacyanoferrate).
\end{abstract}

\section{Introduction}

Progesterone (P4) is a C21 steroid hormone which is secreted by the corpus luteum and is required for creating an environment which is suitable for successful establishment and maintenance of bovine pregnancy (Mondal et al., 2006). P4 concentrations during the oestrus cycle rise and fall depending on the time interval. However, upon establishment of pregnancy, levels remain elevated and for this reason, pregnancy determination via detection of $\mathrm{P} 4(>15 \mathrm{ng} / \mathrm{ml})$ is possible (Balhara et al., 2013) while low P4 concentrations $(<5 \mathrm{ng} / \mathrm{ml})$ have been used to determine oestrous (Mondal et al., 2006). An early diagnosis, ideally at day 21 post artificial insemination, is critical to the maintenance of an efficient breeding program. Despite the advantages of P4 detection in milk for both heat and pregnancy detection, a point-of-care test device suitable for on farm use has yet to be realised.

Recent reports of progesterone immunosensing approaches have involved microfluidics (Arévalo et al., 2010), the use of fluorescent quantum dots (Trapiella-Alfonso et al., 2011), fluoroimmunoassays (Oku et al., 2011), colloidal gold labelling (Carralero et al., 2007a,b;
Monerris et al., 2012) tyrosinase-colloidal gold (Carralero et al., 2007a, b), a colorimetric aptasensor (Du et al., 2016) electrode modified with thionine-graphene oxide composites (Dong et al., 2017) and progesterone detection in milk using a smart phone based reader (Jang et al., 2017). The complexity of the assay formats, reagent addition steps and the surface modifications required limit such methodologies in on-site applications in whole milk. A label free competitive immunosensor approach has the advantage of eliminating the requirements for enzyme substrate addition, taking advantage of the direct signalling associated with the bound conjugate.

The work presented here involves synthesis, characterisation and immunochemical investigations into a novel progesterone derivative that can be ultimately be used to compete with progesterone in a competitive immunoassay format with the aid of electrochemical detection. An ideal conjugate will have redox active behaviour which can be exploited for detection with the aid of techniques such as impedance spectroscopy and voltammetry. Electrochemical impedance spectroscopy forms the electrochemical interrogation tool for this work and reviews by Randviir et al. give an overview of its bioanalytical

\footnotetext{
* Corresponding author.

E-mail address: eithne.dempsey@mu.ie (E. Dempsey).
} 
applications (Randivvir and Banks, 2013). The proposed candidate for conjugation to progesterone is a thio-azide - thiosemicarbazide, with formation of a thiosemicarbazone via a condensation reaction with progesterone. Not only does the molecule have its own inherent redox activity it also has a thione moiety for gold surface interaction, allowing adsorption and immobilisation in an immunosensor format.

Thiosemicarbazide (also known as aminothiourea) is an odourless white crystalline powder and a series of saturated, unsaturated fatty hydrocarbon and aryl substituted thiourea compounds have been synthesised and widely used in analytical chemistry. Thiosemicarbazides can form thiosemicarbazones when they react with particular ketones and aldehydes. Thiosemicarbazones of $\alpha$-(N)-heterocyclic ketones and aldehydes possess a broad spectrum of potentially useful chemotherapeutic activities. Thus, the antimalarial (Biot et al., 2007), antibacterial (Glinma et al., 2011), and antiviral (Pahontu et al., 2015) properties of this class have been explored.

As far as current knowledge extends, there is no conjugation of progesterone to thiosemicarbazide reported in the literature. Glinma et al. (2011) reported a method for the synthesis of thiosemicarbazones (which are often identified by their characteristic $\mathrm{C}=\mathrm{N}$ bond) to various ketones based on the work of Aggarwal et al. (2008). The method presented involved a condensation reaction between a solution of thiosemicarbazide in ethanol which was added slowly to a stirring solution of appropriate carbonyl compound dissolved in ethanol containing glacial acetic acid. Others included work reported by Fatondji et al., 2013) while Murugkar et al. reported the synthesis and characterisation of a testosterone steroid derivate by a condensation reaction between the acetate derivative of testosterone and the hydrochloride salt version of thiosemicarbazide (Murugkar et al., 1999).

In this work, this latter method (Murugkar et al., 1999) was adapted for the optimised synthesis of progesterone acetate thiosemicarbazone. The progesterone starting material was $17 \alpha$-hydroxyprogesterone-17-acetate which was coupled to thiosemicarbazide hydrochloride resulting in progesterone acetate thiosemicarbazone (PATC). Characterisation involved spectroscopic and surface imaging, and an examination of electrochemical and optical properties. PATC was then evaluated as a potential redox active conjugate via anti-progesterone binding studies with the assistance of ELISA and electrochemical impedance spectroscopy measurements. The reaction of thiosemicarbazide at the carbonyl group on the A ring of $\mathrm{P} 4$, results in thione functional group as part of the thiourea group which assists in gold surface adsorption, enabling flexibility as regards the immunoassay format and surface modifiers. The overall objective of the work presented here is to investigation this novel immunoconjugate for its suitability as an electrochemically active conjugate in ELISA development via both optical and impedimetric studies. The research forms the basis for advancement of the assay towards quantitative progesterone sensing in a novel immunosensor format, forming the follow-on phase of the work.

\section{Experimental}

\subsection{Materials}

Progesterone ( $\geq 99 \%), \quad 17 \alpha$-Hydroxyprogesterone $\quad 17$-acetate ( $\geq 98 \%$ ), Thiosemicarbazide $(\geq 99 \%)$ gold(III) chloride trihydrate ( $>99.9 \%)$, sodium nitrite (97\%), sodium nitrate, potassium hexacyanoferrate(III) ( $>99 \%$ ), potassium hexacyanoferrate(II) trihydrate ( $>99.99 \%$ ), potassium phosphate monobasic (99\%), potassium phosphate dibasic (98\%), Acetic Acid ( $\geq 99 \%)$, 4-(2-piperidinoethyl)-3-thiosemicarbazone $(\geq 99 \%)$ and tetrabutylammonium tetrafluoroborate (>99\%) were purchased from Sigma-Aldrich (Ireland). Thiosemicarbazide $(\geq 99 \%)$, thiosemicarbazide hydrochloride were purchased from TCI Europe N.V. Phosphate buffer (PB) was prepared using $0.1 \mathrm{M} \mathrm{KH}_{2} \mathrm{PO}_{4}$ and $0.1 \mathrm{M} \mathrm{K}_{2} \mathrm{HPO}_{4}$ and PBS tablets and PBS- Tween (PBST) was purchased from Sigma Aldrich. All solvents used were purchased from Sigma Aldrich, Lennox Chemicals or VWR. Dimethyl sulphoxide (DMSO) was used as received from VWR and ultra-pure water $(18 \mathrm{M} \Omega$ ) was used in all experiments. Bovine serum albumin (BSA $\geq 96 \%$ ) and 3,3',5,5'-tetramethylbenzidine (TMB liquid substrate for ELISA) were purchased from Sigma Aldrich and used as supplied. Sodium hydrogen carbonate was purchased from the British Drug Houses (BDH), Anti-progesterone antibody (P4-Ab) AbD Serotec and Fitzgerald $(20-1663,8.8 \mathrm{mg} / \mathrm{mL})$ was used together with horseradish peroxidase labelled progesterone (P4-HRP) from Fitzgerald (80-1255, concentration not provided). Commercially available Au screen printed electrodes (SPEs) were purchased from Dropsense and had working electrode area $0.11 \mathrm{~cm}^{2}$.

\subsection{Instrumentation}

The electrochemical experiments (cyclic voltammetry, differential pulse and square wave voltammetry and electrochemical impedance spectroscopy) were performed using an electrochemical workstation $\mathrm{CH}$ Instruments Inc. 750A and $\mathrm{CH}$ Instruments Inc. 760E, using a conventional three electrode cell $(5 \mathrm{~mL})$ at room temperature. A glassy carbon electrode (GCE) (3 mm diameter), Gold (Au) macro disk electrode ( $2 \mathrm{~mm}$ diameter) served as the working electrode, while platinum wire and a standard $\mathrm{Ag} / \mathrm{AgCl}$ electrode (internal solution $3 \mathrm{M} \mathrm{KCl}$ ) were employed as the counter and reference electrodes, respectively. The working electrodes were prepared by polishing with alumina slurries in decreasing size $(0.05,0.3$ and $1.0 \mu \mathrm{m})$ followed by washing in deionised water and air dried. The $\mathrm{Ag} / \mathrm{AgCl}$ reference electrode was stored in concentrated potassium chloride $(3 \mathrm{M} \mathrm{KCl})$ when not in use. For electrochemical characterisation of PATC a non-aqueous reference electrode was prepared using silver nitrate $(10 \mathrm{mM})$ and lithium perchlorate $(0.1 \mathrm{M})$ in methanol. Impedimetric electrochemical characterisation utilised a redox probe, $5 \mathrm{mM}\left[\mathrm{Fe}(\mathrm{CN})_{6}\right]^{3-/ 4-}$ in $0.01 \mathrm{M}$ PBS. Following optimisation on Au macro electrodes, Au screen printed electrodes were subsequently employed for impedance studies. UV-Visible analysis was carried out using a Hitachi U-2900 UV spectrophotometer and BioTek Synergy H1 Hybrid plate reader instruments. Infrared spectroscopy (IR) spectra of the samples were recorded on a Shimadzu IR Prestige-21 with $4 \mathrm{~cm}^{-1}$ resolution at a frequency range of $600-4000 \mathrm{~cm}^{-1}$ in transmittance mode. Solid samples were prepared as dispersions in $\mathrm{KBr}$ discs. NMR spectroscopy was performed using a Bruker Biospin $500 \mathrm{MHz}$ spectrometer operating at $500 \mathrm{MHz}$ (1H NMR) and $125 \mathrm{MHz}$ (13C NMR with a spectral resolution of $0.18 \mathrm{~Hz}$ for $1 \mathrm{H}$ and $0.23 \mathrm{~Hz}$ for 13C). Tetramethylsilane (TMS) was used as an internal standard for $1 \mathrm{H}$ and $13 \mathrm{C}$ NMR, and spectra were processed using TOPSPIN 3.1, with deuterated DMSO as a solvent. NMR chemical shifts are reported in parts per million (ppm, ס). Liquid Chromatography/Mass Spectrometry was performed on an Agilent Technologies 6530 Accurate-Mass Q-TOF LC/MS, utilising the Mass-Hunter workstation software. Samples were dissolved in HPLC grade acetonitrile, with volumes injected between 0.5 and $2.0 \mu \mathrm{L}$. The mobile phase (HPLC grade) used was acetonitrile (70\%), water (30\%), and formic acid $(0.1 \%)$ with flow-rate of $0.5 \mathrm{~mL} / \mathrm{min}$. Thin layer chromatography was performed using Merck aluminium-backed sheets with silica gel 60 F254. The surface morphology of the synthesised derivative PATC was characterised using scanning electron microscopy (HR SEM Auriga). For SEM measurements, samples were suspended in ethanol, sonicated and drop cast onto a copper grid fixed on an Aluminium (Al) stub and coated with gold palladium. Elemental composition was achieved by EDS measurements.

\subsection{Synthesis of progesterone acetate thiosemicarbazone}

Progesterone acetate thiosemicarbazone (PATC) was synthesised using a modification of the procedure reported for the synthesis of testosterone acetate thiosemicarbazone (Murugkar et al., 1999). $17 \alpha$-Hydroxyprogesterone 17 -acetate $(0.003 \mathrm{~mol}, 1.1404 \mathrm{~g})$ was placed into a round bottom flask with minimal amount of methanol and heated 
<smiles>CC(=O)O[C@]1(C(C)=O)CCC2C3CCC4=C/C(=N/NC(N)=S)CC[C@]4(C)C3CC[C@]2(C)C1C(C)=O</smiles>

(B)<smiles>CC(=O)OC1(C(C)=O)CCC2C3CCC4=CC(=NNC(N)=S)CC[C@]4(C)C3CC[C@]21C</smiles><smiles>CC(=O)OC1(C(C)=O)CCC2C3CCC4=CC(NNC(N)=S)CC[C@]4(C)C3CC[C@]21C</smiles>

(C)

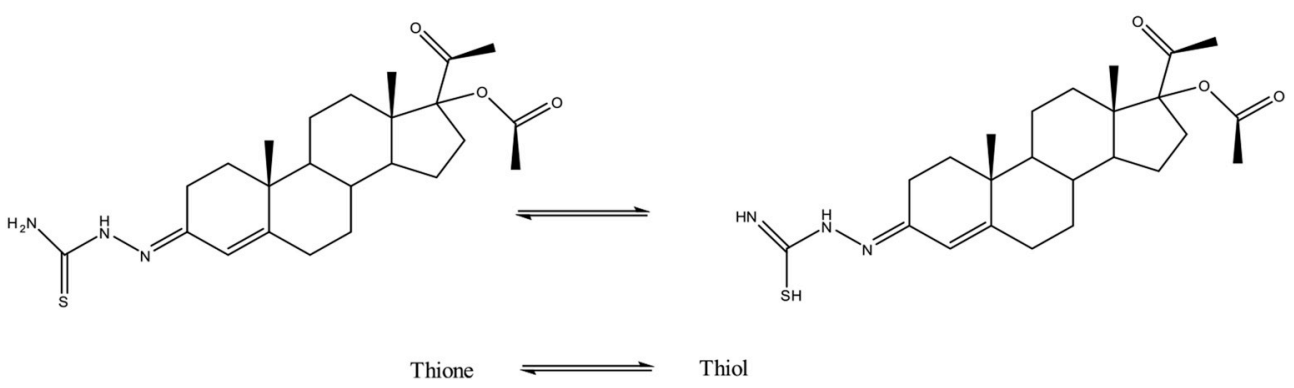

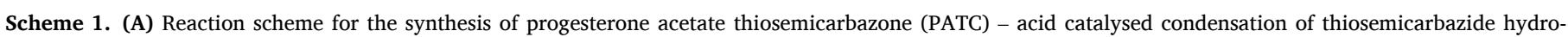

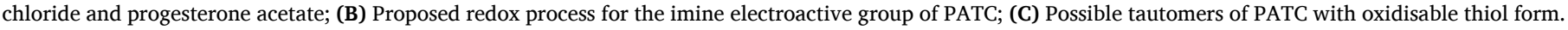

until it had dissolved. Thiosemicarbazide hydrochloride $(0.003 \mathrm{~mol}$, $0.39 \mathrm{~g}$ ) was dissolved in deionised water (approx. $10 \mathrm{~mL}$ ). The thiosemicarbazide hydrochloride solution was added to the alcoholic $17 \alpha$-Hydroxyprogesterone 17 -acetate solution in the round bottom flask. The reaction mixture was refluxed $\left(60^{\circ} \mathrm{C}\right)$ with continuous stirring for $6 \mathrm{~h}$. The solution was allowed to cool (approx. $48 \mathrm{hr}$.) until a precipitate appeared. The solvent was discarded by filtration, followed by sufficient washing with cold ethanol and cold deionised water. The crude product was recrystallised in minimal hot ethanol (Scheme 1(A)) and $\%$ yield was $64 \%$.

\subsection{Electrochemical characterisation of progesterone acetate thiosemicarbazone}

Cyclic voltammetry was performed in methanol/0.1 $\mathrm{M} \mathrm{LiClO}_{4}$ at a scan rate of $100 \mathrm{mVs}^{-1}$ over a fixed potential window of $+1.0 \mathrm{~V}$ to $-1.0 \mathrm{~V}$ $v s$. $\mathrm{Ag} / \mathrm{AgCl}$. Differential pulse voltammetry employed a potential range of $0.3-1.0 \mathrm{~V} v s . \mathrm{Ag} / \mathrm{Ag}^{+}$with an increment of $0.004 \mathrm{~V}$ and amplitude $0.05 \mathrm{~V}$. Adsorptive anodic stripping voltammetry at both GCE and Au electrodes was performed using cathodic accumulation at $-1.0 \mathrm{~V}$ for 200 $\mathrm{s}$ followed by an anodic differential pulse sweep. Prior to protein functionalisation, electrodes were subjected to a mild anodic treatment in phosphate buffer ( $0.1 \mathrm{M}, \mathrm{pH}$ 6.0) electrolyte. This was achieved by scanning electrodes between 0 and $+1.0 \mathrm{~V} v s$. Ag/AgCl for 10 cycles, a process which resulted in surface activation.

\subsection{Electrochemical impedance spectroscopy at Au macro and screen printed electrodes}

The AC electrochemical impedance (EIS) response was measured in a solution containing $5 \mathrm{mM}\left[\mathrm{Fe}(\mathrm{CN})_{6}\right]^{3-/ 4-}$ in $0.01 \mathrm{MPB}$ with the alternating potential set to the appropriate formal potential of the redox couple $(0.21 \mathrm{~V} v$ s. $\mathrm{Ag} / \mathrm{AgCl}$ for $\mathrm{Au}$ macro electrode and $0.08 \mathrm{~V}$ for $\mathrm{Au}$ screen printed electrodes), over the frequency range $0.1-105 \mathrm{~Hz}$. A background $\mathrm{CV}$ was recorded in the redox probe over the range -0.2 to $0.5 \mathrm{~V}$ at $100 \mathrm{mV} / \mathrm{s}$ (6 cycles) in $5 \mathrm{mM}\left[\mathrm{Fe}(\mathrm{CN})_{6}\right]^{3-/ 4}$. An EIS spectrum was then recorded in the redox probe solution following which the electrode was gently rinsed with deionised water and the impedance $\mathrm{Z}$ expressed as real $\left(\mathrm{Z}^{\prime}\right)$ or imaginary $\left(\mathrm{Z}^{\prime \prime}\right)$ components. In order to confirm recognition of anti-P4 towards the antigenic moieties of PATC, two 


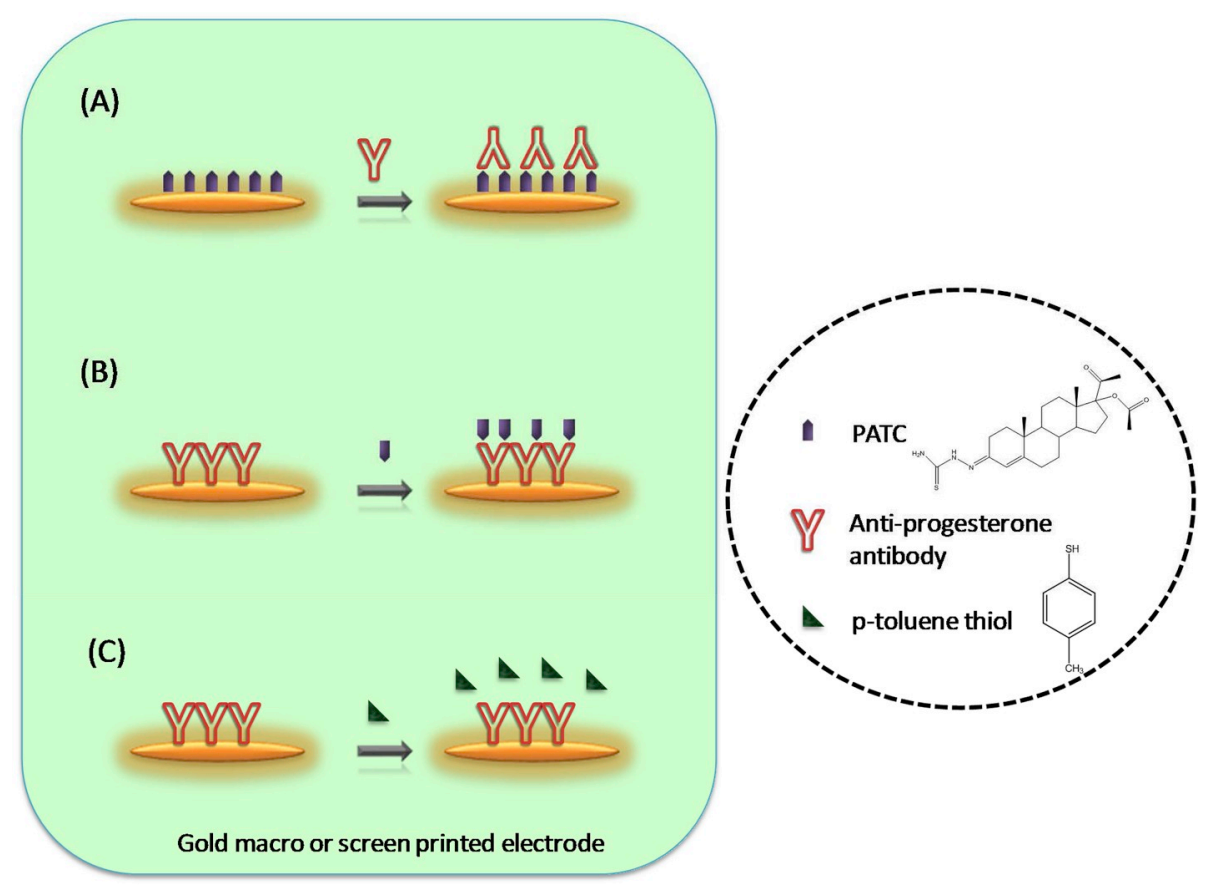

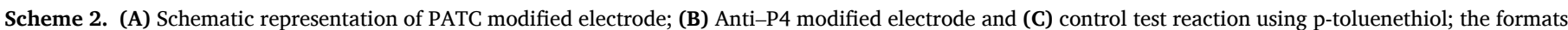
enabled binding investigations and all surfaces were blocked using BSA.

electrode formats (A) and (B) were employed as outlined below and surface charge transfer/impedance changes $\left(\Delta \mathrm{R}_{\mathrm{CT}}\right)$ monitored with data presented as both Nyquist and Bode plots.

(A) Immobilisation of PATC on Gold transducers as primary adsorbed layer for binding confirmation

In order to optimise loading and incubation time for PATC adsorption on Au surfaces the electrode was immersed in $100 \mu \mathrm{L}$ of PATC over the range $0.01-10.0 \mu \mathrm{M}$, overnight $(15 \mathrm{~h})$ both at $4{ }^{\circ} \mathrm{C}$ and room temperature. After the specified incubation period the electrode was rinsed gently and the response ( $\mathrm{CV} \&$ EIS) measured under the conditions as described above. The modified electrode was then blocked with $1 \%$ BSA in PBS at room temperature for $0.5 \mathrm{~h}$ following which the electrode was rinsed with DI and CV and EIS experiments were performed. The final modification step involved the introduction of the anti-progesterone antibody (Anti-P4) $(1.5,3.0$ and $6.0 \mu \mathrm{g} / \mathrm{mL}, 100 \mu \mathrm{L})$ which was carefully pipetted on the electrode surface and allowed incubate at $37^{\circ} \mathrm{C}$ for $1.5 \mathrm{~h}$ followed by gentle rinsing. The so-formed electrode is labelled $\mathrm{Au} /$ PATC/BSA/Anti-P4 (Scheme 2 (A)).

(B) Immobilisation of Anti-P4 antibodies on gold transducers as primary adsorbed layer for binding confirmation

In this format the initial modification step involved antiprogesterone antibody (Anti-P4) (1.5, 3.0 and $6.0 \mu \mathrm{g} / \mathrm{mL}, 100 \mu \mathrm{L})$ which was carefully pipetted on the electrode surface and allowed incubate at $37^{\circ} \mathrm{C}$ for $1.5 \mathrm{~h}$ followed by gentle rinsing with deionised water. The electrode [Au/Anti-P4] was then blocked using a nonspecific blocking agent bovine serum albumin (BSA) (1\% in PBS, $100 \mu \mathrm{L}$ ) - with incubation at room temperature for $0.5 \mathrm{~h}$ followed by rinsing with deionised water. A CV and EIS response were then recorded. The final modification step involved incubation ( 1 h at RT) with $100 \mu \mathrm{L}$ of PATC solution ( $3 \mu \mathrm{M}$ was found to be optimum in this format) dissolved in phosphate buffer. The electrode was rinsed gently to remove any non-specifically bound PATC and the CV and EIS response measured. All modifications were confined to the working electrode area. A schematic for this experimental set-up can be seen in Scheme 2
(B) and the electrode is labelled Au/Anti-P4/BSA/PATC. As a control experiment the above procedure was repeated with the introduction of para-toluenethiol solution $(3.0 \mu \mathrm{M}, 200 \mu \mathrm{L})$ as the final step (incubation for $1 \mathrm{~h}$ at RT). Para-toluenethiol was selected due to its sulfur moiety with gold affinity, albeit lacking the specific antigenic sites of the PATC molecule which facilitate antibody recognition at the Fab protein regions (Scheme 2(C)).

\subsection{Competitive ELISA procedure utilising PATC conjugate with optical detection}

Anti-progesterone solution (prepared in carbonate buffer, $3.0 \mu \mathrm{g} / \mathrm{mL}$ $\mathrm{pH}$ 9.6) was introduced to the wells of a 96 well plate $(100 \mu \mathrm{L})$ and incubated for $1 \mathrm{~h}$ at $37^{\circ} \mathrm{C}$ with the exception of the control wells. Excess solution was then removed and the plate was air dried for $1 \mathrm{~h}$ before blocking ( 5 min incubations with $1 \%$ BSA-PBST solution, $300 \mu \mathrm{L}, \mathrm{x} 3$ ) and leaving the plate to air dry for an hour at room temperature before use. $10 \mu \mathrm{L}$ of progesterone standards $(0-50 \mathrm{ng} / \mathrm{mL}$ in phosphate buffer $\mathrm{pH}$ 7.4) were added to the wells together with $100 \mu \mathrm{L}$ of P4-horseradish peroxidise (HRP) conjugate (1:1600 dilution) and incubated at room temperature for $1 \mathrm{~h}$. Excess solution was disposed of and wells were washed with PBST (x3, $300 \mu \mathrm{L}$ ) before adding $100 \mu \mathrm{L}$ of substrate (TMB) and incubating at room temperature for $15 \mathrm{~min}$ allowing a blue colour to develop. The enzyme reaction was quenched with $\mathrm{HCl}$ stop solution resulting in a colour change from blue to yellow with measurement of absorbance intensity at $450 \mathrm{~nm}$.

\section{Results and discussion}

\subsection{Characterisation of progesterone acetate thiosemicarbazone}

The synthesised steroidal derivative progesterone acetate thiosemicarbazone (PATC) was characterised using spectroscopic, electrochemical, elemental and surface techniques as detailed below.

\subsubsection{Spectroscopic analysis}

The FTIR spectrum of PATC is shown in Supplementary data (ESM 1) and indicated the absence of the cyclic carbonyl group (at $1662.64 \mathrm{~cm}^{-}$ 
(A)

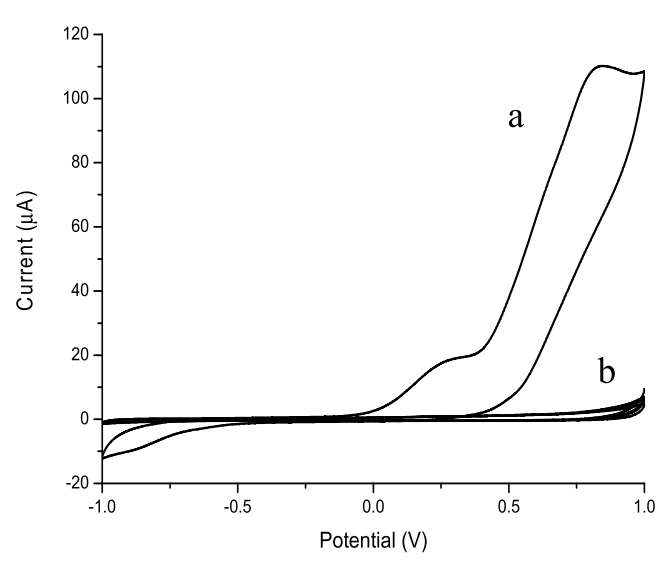

(C)

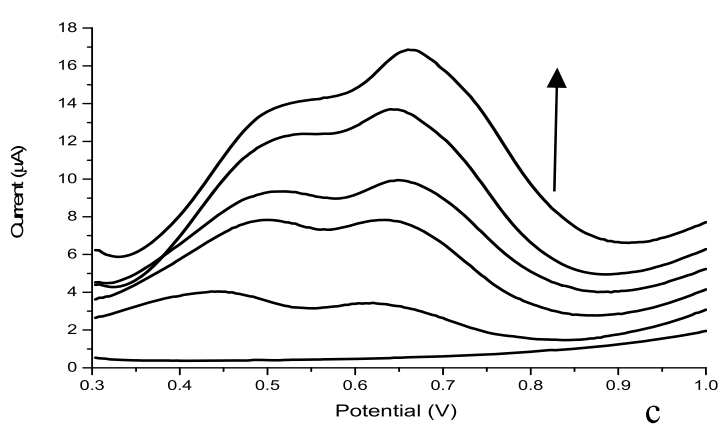

(B)

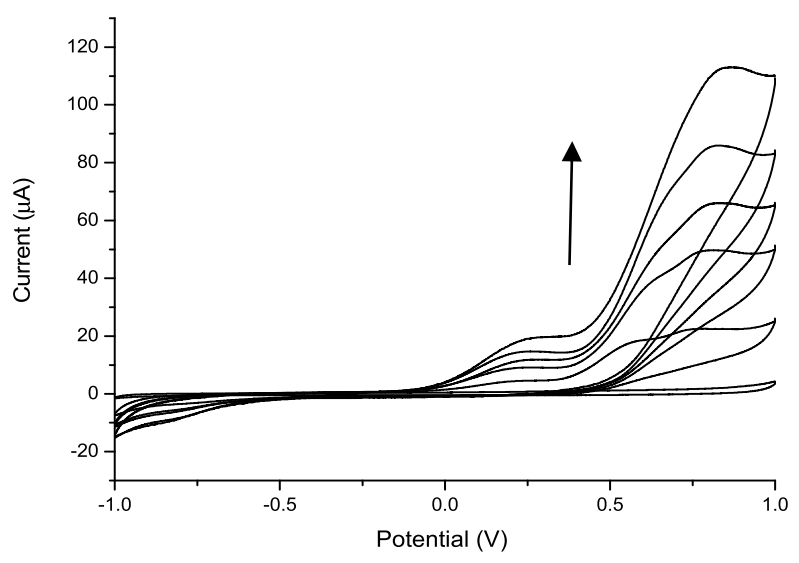

(D)

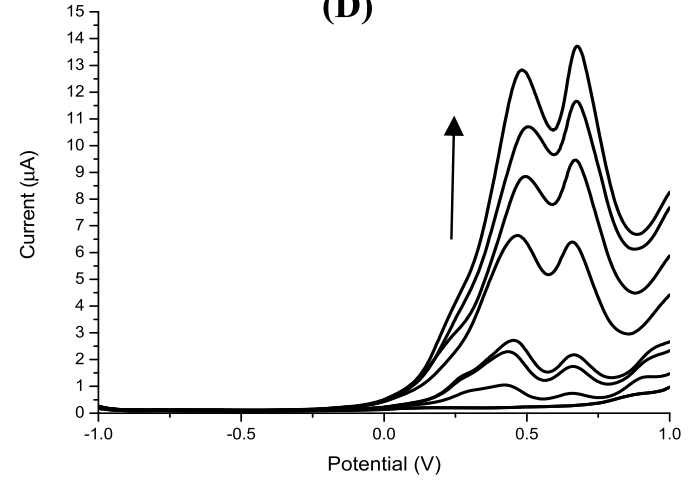

Figure 1. (A) CV of (a) PATC ( $2.5 \mathrm{mM}$ ) overlaid with starting reagents (b) progesterone $(2.5 \mathrm{mM})$ and (c) progesterone acetate $(2.5 \mathrm{mM})$ over the range $-1.0-+1.0 \mathrm{~V}$ vs. $\mathrm{Ag} / \mathrm{Ag}^{+}$at a GCE; scan rate $100 \mathrm{mV} / \mathrm{s}\left(0.1 \mathrm{M} \mathrm{LiClO}_{4} /\right.$ methanol); (B) Voltammetric response to increasing PATC concentrations over the range 0.5-2.5 mM; potential range $-1.0-+1.0 \mathrm{~V}$ vs. $\mathrm{Ag} / \mathrm{Ag}^{+}$at a GCE; scan rate $100 \mathrm{mV} / \mathrm{s}(0.1 \mathrm{M} \mathrm{LiClO} 4 /$ methanol); (C) DPV of PATC (0.5 mM-2.5 mM) at a GCE electrode over a potential range of -0.3 and $1.0 \mathrm{~V}$ vs Ag/ $\mathrm{Ag}^{+}$, increment $0.004 \mathrm{~V}$, amplitude $0.05 \mathrm{~V}$ in $0.1 \mathrm{M} \mathrm{LiClO} / \mathrm{methanol}$ (D) DPVS of PATC (0.0625 mM-2.5 mM) at GCE over a potential range of -1.0 to $1.0 \mathrm{~V}$ vs Ag/ $\mathrm{Ag}^{+}$, increment $0.004 \mathrm{~V}$, amplitude $0.05 \mathrm{~V}$ in $0.1 \mathrm{M} \mathrm{LiClO} / \mathrm{methanol}$. Cathodic deposition involved holding the potential at $-1.0 \mathrm{~V}$ for $200 \mathrm{~s}$

${ }^{1}$ ), present in progesterone acetate starting material and the presence of a stretch at $1629.04 \mathrm{~cm}^{-1}$ that was absent in any of the starting materials, being indicative of a $\mathrm{C}=\mathrm{N}$ bond (literature value of $1633-1587 \mathrm{~cm}^{-1}$ (Glinma et al., 2011). Strong stretches were also witnessed at $1084.55 \mathrm{~cm}^{-1}(\mathrm{C}=\mathrm{S})$ and $869.90 \mathrm{~cm}-1$ (N-CS-N) which relates to a stretch for a thioamide group (literature values $1123-845 \mathrm{~cm}^{-1}$ ) (Glinma et al., 2011).

3.1.1.1. Mass spectroscopy analysis. The MS spectrum can be seen in Supplementary data (ESM 2) where an $\mathrm{m} / \mathrm{z} 446.25\left(\mathrm{M}^{+} \mathrm{H}\right)$ indicates a structure with a molecular weight of $445.24 \mathrm{~g} / \mathrm{mol}$ with a molecular formula of $\mathrm{C}_{24} \mathrm{H}_{35} \mathrm{~N}_{3} \mathrm{O}_{3} \mathrm{~S}$.

3.1.1.2. NMR analysis. The ${ }^{13} \mathrm{C}$ NMR spectra is shown in (ESM 3) with a $\mathrm{C}=\mathrm{S}$ peak at $178.75 \mathrm{ppm}$ and the presence of a signal for $\mathrm{C}=\mathrm{N}$ at $150.79 \mathrm{ppm}$. The spectra also illustrates the absence of the signal for the cyclic carbonyl $(\mathrm{C}=\mathrm{O})$ at $198.43 \mathrm{ppm}$ which was present in the ${ }^{13} \mathrm{C} N \mathrm{NR}$ spectra of the progesterone acetate starting material (complete assignment can be seen in ESM 3). Overall NMR interpretation indicates a successful condensation reaction due to appearance of the imine $\mathrm{C}=\mathrm{N}$ bond formation and the lack of cyclic ketone $\mathrm{C}=\mathrm{O}$ (progesterone acetate). As the $\beta$ amino group of thiosemicarbazide is more nucleophilic that the $\mathrm{NH}_{2} \alpha$ to the thione functional group, covalent attachment occurs at this position and isomers are unlikely.
3.1.1.3. UV analysis. PATC dissolved in ethanol (200-800 nm) showed $\lambda_{\text {max }}$ at $334 \mathrm{~nm}\left(\varepsilon=0.0288 \mu^{-1} \mathrm{~mL} \mathrm{~cm}^{-1}\right)$. This peak was not present in the compared spectra for starting materials (ESM 4).

\subsubsection{Surface analysis}

SEM and EDX analysis (ESM 5) together provide information regarding morphology and elemental composition. SEM images confirm the amorphous nature of the material while elemental identification was in agreement with the synthetic composition. The presence of sulfur was attributed to the thione group and presence of nitrogen confirmed the successful conjugation of the thiosemicarbazide to the progesterone acetate, while the oxygen signal indicates that the acetate and acyclic ketone still exist (the presence of copper was due to the copper grid used for sample preparation).

\subsubsection{Electrochemical characterisation}

The electroactivity of PATC was investigated in a non-aqueous electrolyte $-0.1 \mathrm{M} \mathrm{LiClO}_{4}$ in methanol. 1, 2 and $5 \mathrm{mM}$ PATC was dissolved in the electrolyte solution and degassed under Argon (10 min). The cyclic voltammetric response was examined at three different working electrodes over the potential range -0.2 to $1.0 \mathrm{~V}$ at $0.1 \mathrm{~V} / \mathrm{s}$ resulting in two irreversible anodic processes at a glassy carbon electrode (GCE) (Fig. $1 \mathrm{~A}$ and $\mathrm{B})\left(\mathrm{E}_{\mathrm{p}}=0.25\right.$ and $0.75 \mathrm{~V}$ vs. $\mathrm{Ag} / \mathrm{Ag}^{+}$) which increased with increasing concentration $(0.5-2.5 \mathrm{mM})$. Scan rate studies verified a diffusion controlled irreversible process which may be 


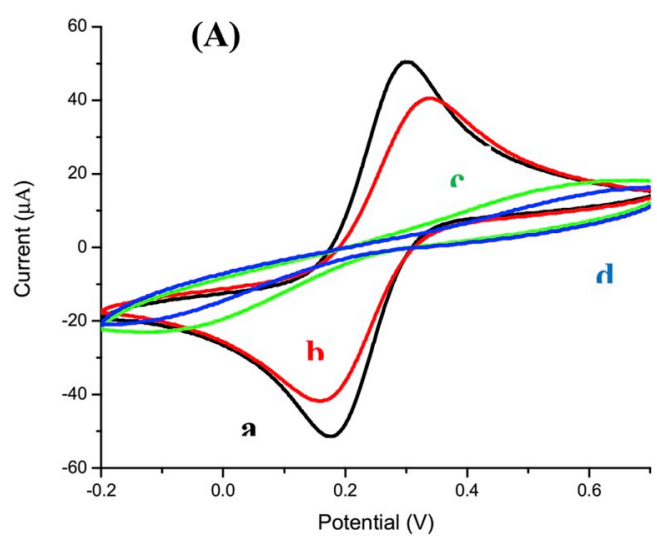

(B)



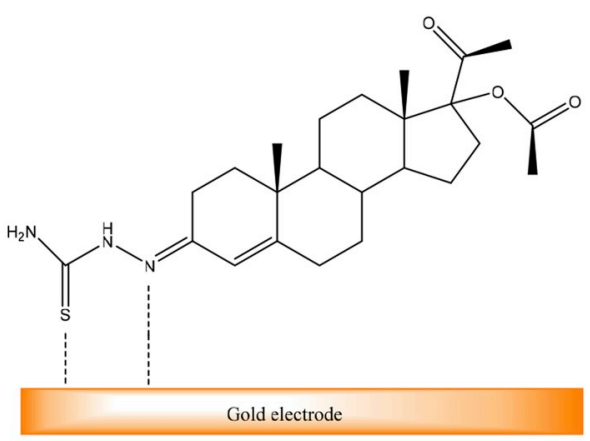

(C)
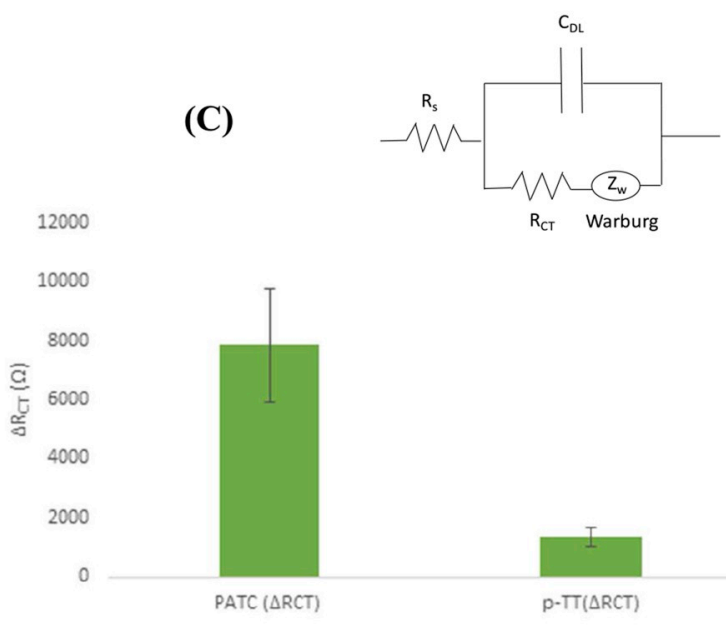

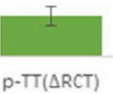

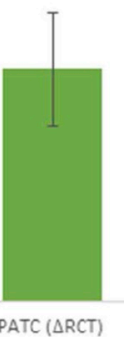

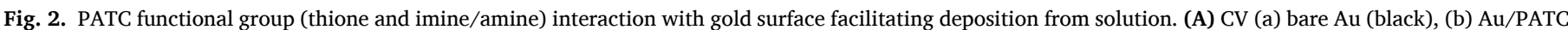

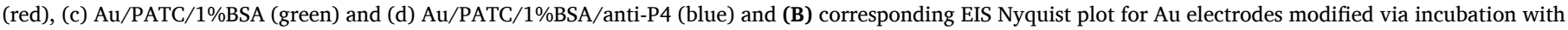

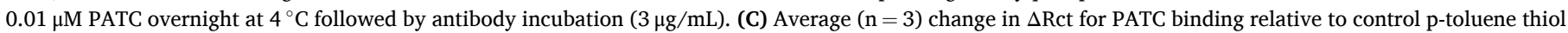

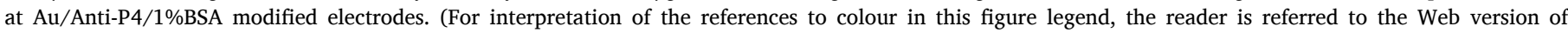
this article.)

described by Equation (1) below (Kissinger and Heineman, 1996).

$I_{p}=\left(2.99 \times 10^{5}\right) n \sqrt{\alpha n_{a}} A \sqrt{D} C^{o} \sqrt{\nu}$

Where $\alpha$ is the transfer co-efficient, $\mathrm{n}_{\mathrm{a}}$ is the number of electrons in the rate determining step, $\mathrm{D}_{0}$ is the diffusion co-efficient and $v$ is scan rate. Taking $D_{o}$ as $1 \times 10^{-5} \mathrm{~cm}^{2} / \mathrm{s}$ and based on a 1 electron process $\alpha$ can be estimated at 0.25 . This value correlates well with that found based on the difference between $\mathrm{E}_{\mathrm{p}}(0.75 \mathrm{~V})$ and $\mathrm{E}_{\mathrm{p} / 2}(0.564 \mathrm{~V})$ for an irreversible system (Equation (2).

$E_{p}-E_{\frac{p}{2}}=\frac{1.857 R T}{\alpha n_{a} F}$

Equation (3) allows determination of $\mathrm{k}^{\mathrm{o}}$ (standard heterogeneous rate constant) for an irreversible process (Kissinger and Heineman, 1996).

$k^{o}=2.415 \exp \left(-0.02 \frac{F}{R T}\right) \sqrt{D_{o}} \frac{1}{\sqrt{\left(E_{p}-E_{P / 2}\right)}} \sqrt{v}$

Where $\mathrm{R}$ is the gas constant, $\mathrm{T}$ is temperature and $\mathrm{F}$ is Faraday's constant. Taking $\mathrm{E}_{\mathrm{p}}$ for the most dominant anodic process at $0.75 \mathrm{~V}$ and $\mathrm{E}_{\mathrm{p} /}$
${ }_{2}$ at $0.564 \mathrm{~V}$ this results is a $\mathrm{k}^{\mathrm{o}}$ value of $2.56 \times 10^{-3} \mathrm{~cm}^{2} / \mathrm{s}$ at $\nu=100 \mathrm{mV} /$ s.

Differential pulse voltammetry (DPV) and adsorptive stripping mode DPV was performed at a GCE over the range $0.5-2.5 \mathrm{mM}$ and resulted in split peaks $\mathrm{I}\left(\mathrm{E}_{\mathrm{p}}=0.45 \mathrm{~V}\right.$ vs. $\left.\mathrm{Ag} / \mathrm{Ag}^{+}\right)$and II $\left(\mathrm{E}_{\mathrm{p}}=0.62 \mathrm{~V}\right.$ vs. $\left.\mathrm{Ag} / \mathrm{Ag}^{+}\right)$ (Fig. 1C), which became more defined when a cathodic deposition step preceded the anodic sweep (Fig. 1D). The anodic processes may be attributed to the oxidation of the imine or thioamide groups present in the compound (see proposed Scheme 2(B)). We have also considered two possible tautomers of PATC vis thione and thiol forms (Scheme $2(\mathrm{C})$ ) - the more anodic oxidation wave may coincide with disulphide formation upon oxidation of the thiol form (Khan et al., 2014). With an increase in concentration, there was an increase in peak currents at $0.45 \mathrm{~V}$ (I) and $0.65 \mathrm{~V}$ (II) resulting in a linear relationship between current and concentration with sensitivity of $2.14 . \mu \mathrm{A} / \mathrm{cm}^{2} / \mathrm{mM}$, $\mathrm{r}^{2}=0.985(\mathrm{n}=3)$. Though GCE electrodes provided the optimum PATC redox behaviour for this study, a concentration dependant single peak at $0.6 \mathrm{~V} v s . \mathrm{Ag} / \mathrm{Ag}^{+}$was evident in the case of PATC DPV response at $\mathrm{Au}$ macroelectrodes with sensitivity $1.72 \mu \mathrm{A} / \mathrm{mM}$ over the same range. 


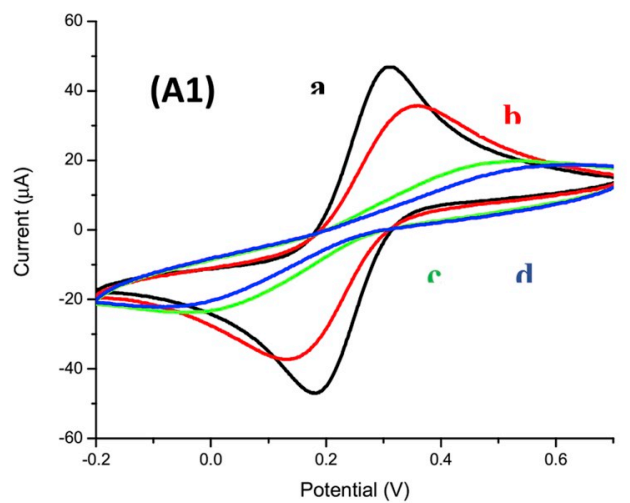

(B1)
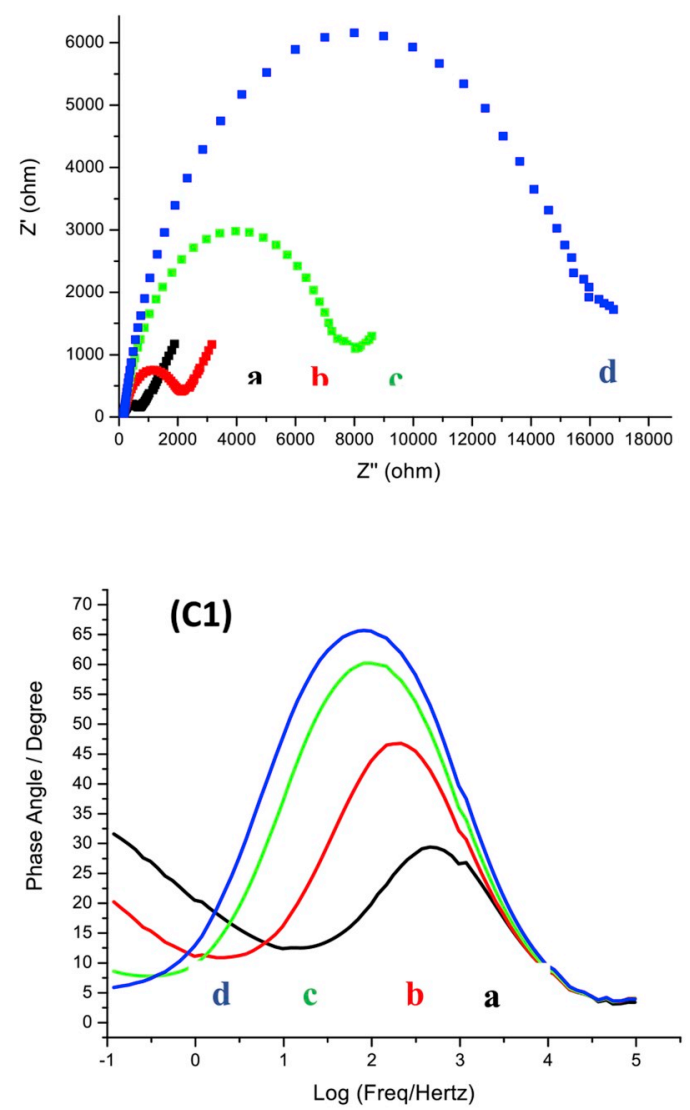

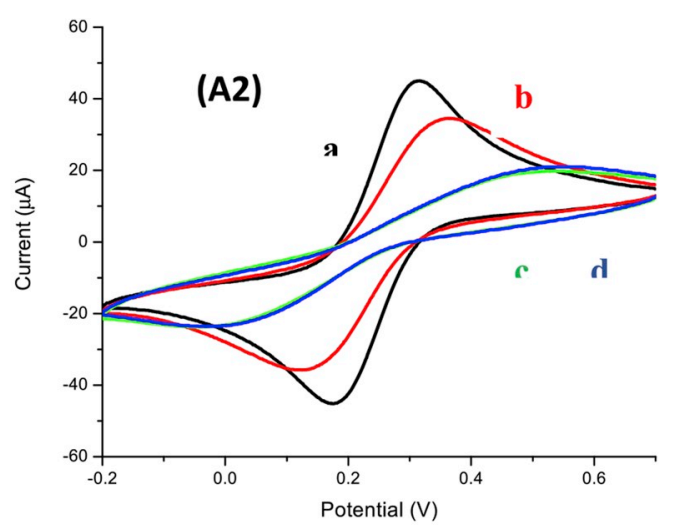

(B2)
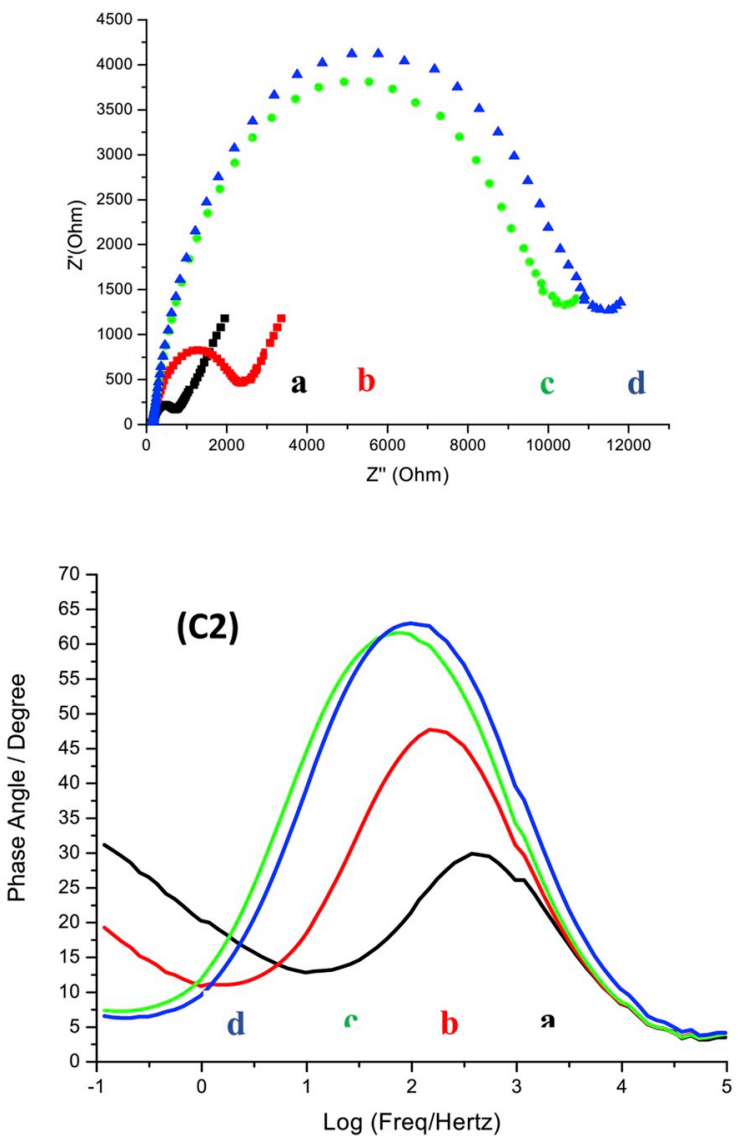

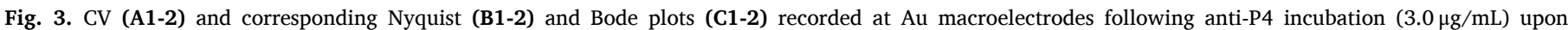

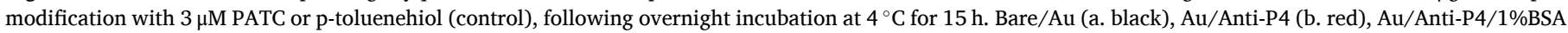

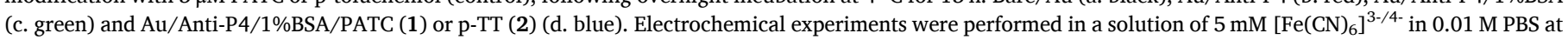

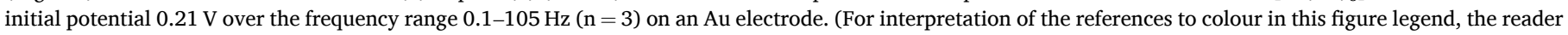
is referred to the Web version of this article.)

\subsection{ELISA competitive assay - progesterone antibody binding investigation utilising PATC conjugate}

The competitive ELISA format (progesterone-horseradish peroxidase conjugate $v s$. PATC) was established according to the procedure outlined in section 2.6. In the absence of antigen a strong blue/yellow colour developed and little or no colour change was observed in the presence of high concentrations of progesterone. Results shown in ESM 6 confirmed that with an increase of PATC concentration there was a decrease in absorbance signal due to fewer anti-P4 binding sites being available for conjugation to the HRP enzyme labelled progesterone. Column 6 in the tabulated data in (ESM 6) represents the control line (no immobilised anti-progesterone antibody) in the ELISA experiment. A calibration curve with a linear regression value of 0.98 for a concentration range of 0-5 $\mu \mathrm{M}$ PATC (0.144 AU/ $\mu \mathrm{M}$ sensitivity) was determined confirming that the PATC progesterone analogue was recognised by antiprogesterone antibodies proving its validity as a candidate for competition with free progesterone.

\subsection{Electrochemical impedance spectroscopy}

The electrochemical cell was modelled according to the simplified 

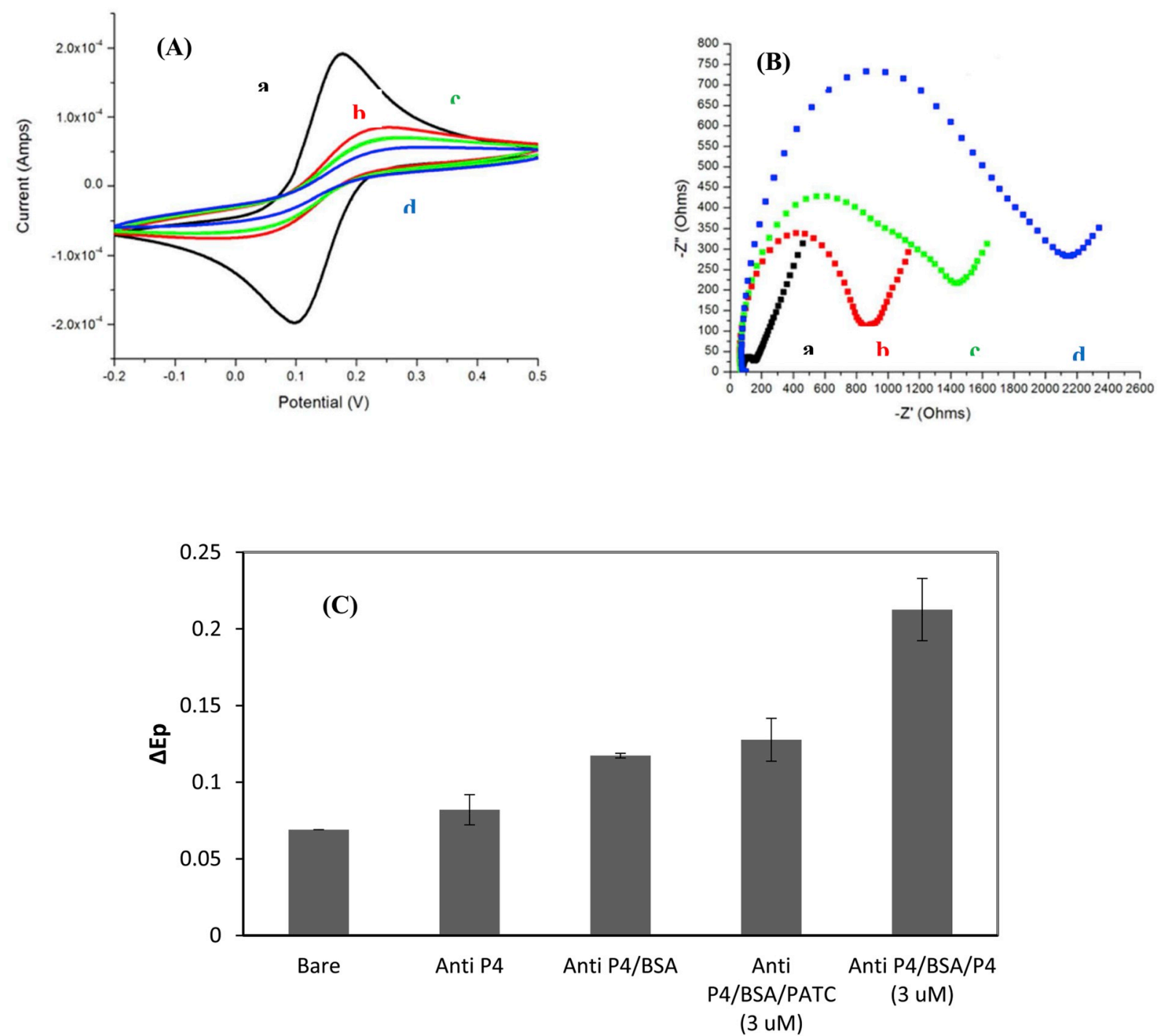

Fig. 4. (A) CV and corresponding Nyquist (B) response recorded at a Au SPE following antibody incubation under same conditions as Fig. $3.5 \mathrm{mM}\left[\mathrm{Fe}\left(\mathrm{CN}_{6}\right]^{3-/ 4-}\right.$ in $0.01 \mathrm{M}$ PBS at initial potential $0.12 \mathrm{~V}$ over the frequency range 0.1-105 Hz. Bare/Au (a. black), Au/Anti-P4 (b. red), Au/Anti-P4/1\%BSA (c. green) and Au/Anti-P4/ $1 \%$ BSA/PATC (d. blue). Chart (C) shows the changes in $\triangle \mathrm{Ep}$ (redox probe study) upon surface modification with the inclusion of progesterone ( $3 \mu \mathrm{M})$ confirming successful discrimination between progesterone and its analogue PATC. (For interpretation of the references to colour in this figure legend, the reader is referred to the Web version of this article.)

Randles circuit for a system with mixed kinetic and diffusion limited processes; where $R_{s}$ is solution resistance, $C_{d l}$ represents double layer charging and $\mathrm{R}_{\mathrm{CT}}$ is redox probe charge transfer resistance - opposition to electron movement (kinetic control). Warburg impedance $\left(\mathrm{Z}_{\mathrm{w}}\right)$ represents diffusion (mass transfer control) of solution ions to the electrode surface and is related to the heterogeneous electron transfer rate constant $\left(\mathrm{k}^{\mathrm{O}}\right)$ by Equation (4) below for a one electron process ( $\mathrm{R}$ is the gas constant, $\mathrm{T}$ is temperature, $\mathrm{F}$ is Faraday's constant and $\mathrm{C}$ is the concentration of the electroactive species).

$R_{C T}=\frac{R T}{F^{2} k^{o} C}$

Format (A) (Scheme 2A) above, involving direct PATC adsorption onto the Au surface, enabled an examination of $\mathrm{Ab}-\mathrm{Ag}$ binding events and facilitated optimisation of conditions for the conventional immunosensor format (B) (Scheme 2B), which was then translated onto an Au screen printed electrode surface. Incubation of $0.01-10 \mu \mathrm{M}$ PATC at both $\mathrm{RT}$ and $4{ }^{\circ} \mathrm{C}$ (overnight) resulted in increases in $\mathrm{R}_{\mathrm{CT}}$ from 800 to $2500 \Omega$ (Nyquist plots not shown) with improved signal reproducibility and stability following incubation at $4{ }^{\circ} \mathrm{C} .3 \mu \mathrm{M}$ PATC was selected for optimisation of incubation time (1,4 and $15 \mathrm{~h})$ for the Au-PATC surface adsorption process resulting in no significant variation in $\mathrm{R}_{\mathrm{CT}}$. However, the most robust and stable impedance signals were achieved when $\mathrm{Au}$ electrodes were incubated in PATC overnight $\left(15 \mathrm{~h}\right.$ at $\left.4{ }^{\circ} \mathrm{C}\right)$ and this approach was employed going forward.

Using this format (Au/PATC/BSA/Anti-P4), antibody levels were examined over the range $1.5-6 \mu \mathrm{g} / \mathrm{mL}$ in order to both verify binding and assess impact of antibody level on the magnitude of alterations in $\mathrm{R}_{\mathrm{CT}}$. Fig. 2 shows $\mathrm{CV}$ data in the redox probe $\left(\mathrm{Fe}^{2+/ 3+}\right)$ with corresponding Nyquist plots resulting in significant increases in $\mathrm{R}_{\mathrm{CT}}$ following blocking [(from $334.9 \Omega$ to $16450 \Omega$ (following BSA adsorption) to $18870 \Omega+/$ - (following anti-P4 interaction)]. $\Delta \mathrm{E}_{\mathrm{p}}$ changes were from $0.11 \mathrm{~V}$ (bare) to $0.154 \mathrm{~V}$ (Au/PATC) to $0.498 \mathrm{~V}$ (Au/PATC/BSA) to $0.519 \mathrm{~V}$ (Au/PATC/BSA/Anti-P4). Based on this result and data derived from Format (B) (and ELISA checkerboard assay), an anti-P4 level of $3.0 \mu \mathrm{g} / \mathrm{mL}$ was deemed to be most suitable for further use. Rate constants for heterogeneous electron transfer $\left(\mathrm{k}^{\mathrm{O}}\right)$ were calculated from average $R_{C T}$ values for the various surfaces resulting in $1.59 \times 10^{-4} \mathrm{~cm}^{3}$ / $\mathrm{s}$ (bare Au), $7.67 \times 10^{-5} \mathrm{~cm}^{3} / \mathrm{s}$ (upon adsorption of PATC), $3.23 \times 10^{-}$ $5 \mathrm{~cm}^{3} / \mathrm{s}$ following BSA addition and $2.82 \times 10^{-6} \mathrm{~cm}^{3} / \mathrm{s}$ upon antibody 
interaction. The average changes in $\mathrm{R}_{\mathrm{CT}}$ values $(\mathrm{n}=3)$ upon adsorption of control species para-toluenethiol in comparison to PATC binding is also shown in Fig. 2, indicating the lack of significant $\Delta R_{C T}$ changes in the case of the control system.

Impedimetric and voltammetry data for the Format (B) Scheme 2(B) (Au/Anti-P4/BSA/PATC), confirms the affinity of anti-P4 for the progesterone derivative PATC upon exposure to an antibody modified gold electrode surface. The Bode plots (Fig. $3 \mathrm{C} 1$ and C2) showed increased impedance at high frequencies with the expected shift in phase angle corresponding to increased surface loading/interaction over the range examined. This matches the Nyquist and redox probe data, (Fig. 3A, B), while there was no significant change in impedance with respect to either $\mathrm{R}_{\mathrm{CT}}$ or phase angle following introduction of the control species $\mathrm{p}$ toluene thiol to the antibody modified Au surface.

Gold screen printed electrodes (Au SPE) were subjected to the same immunoreagent loading under optimum conditions, involving antiprogesterone antibody $(3.0 \mu \mathrm{g} / \mathrm{mL}, 10 \mu \mathrm{L})$. The electrode (AuSPE/AntiP4) was then blocked with BSA ( $1 \%$ in PBS, $10 \mu \mathrm{L}$ ) at room temperature for $0.5 \mathrm{~h}$. The final modification step involved the introduction of PATC in PBS $(3.0 \mu \mathrm{M}, 10 \mu \mathrm{L})$ which was allowed to incubate for $1 \mathrm{~h}$ at $37^{\circ} \mathrm{C}$. The CV and EIS response was measured following each modification step and results are presented in Fig. 4, (A) CV data (B) Nyquist plot and (C) $\triangle \mathrm{Ep}$ from redox probe study showing difference between PATC and progesterone surface interactions. Upon inspection of the data, identical trends were observed and changes in $\mathrm{R}_{\mathrm{CT}}$ were of the same magnitude as that at the macro Gold electrode $65.84 \Omega$ (bare Au SPE), $710.7 \Omega$ (following antibody binding to AuSPE), $987.5 \Omega$ following the blocking step and increasing to $1601 \Omega$ upon introduction of PATC. Corresponding rate constants were $8.08 \times 10^{-4} \mathrm{~cm}^{3} / \mathrm{s}, 7.49 \times 10^{-5} \mathrm{~cm}^{3} / \mathrm{s}, 5.44 \times 10^{-}$ $5 \mathrm{~cm}^{3} / \mathrm{s}$ and $3.32 \times 10^{-5} \mathrm{~cm}^{3} / \mathrm{s}$ respectively; the latter two modification stages resulting in $\mathrm{k}^{\mathrm{O}}$ values which were approximately an order of magnitude higher than those at the Au macro electrode. The greatest change in the charge transfer resistance was recorded at the final step of modification when PATC was introduced confirming binding affinity and creation of an immuno-complex. The CV data (Fig. 4 (A)) clearly illustrates a decrease in the $\Delta \mathrm{E}_{\mathrm{p}}$ with each step of modification; this complements the EIS data presented in the Nyquist (B) plot. There was a significant increase in the charge transfer resistance at each step of modification (B) as well as an increase in the phase angle (data not shown) and a slight shift towards higher frequencies suggesting the formation of the antigen-antibody immuno-complex. Fig. 4 (C) shows the relative changes in peak potential for each surface layer with the inclusion of the progesterone steroid molecule $(3 \mu \mathrm{M})$ confirming the higher extent of surface interaction relative to PATC as expected. This promising result provides evidence of the successful translation of the immunoreagents to Au SPEs with retention of the expected bioaffinity, as evident from EIS and redox probe data while correlating with ELISA results.

\section{Conclusion}

Synthesis (yield 64\%), characterisation and electrochemical evaluation of a novel progesterone derivative PATC has been successfully achieved. The compound was characterised via spectroscopic, electrochemical, imaging and elemental techniques. Irreversible redox activity was examined using both voltammetric and pulse techniques with the view to potentially exploiting surface confined PATC electrochemical signals upon immunocompetition with P4 and subsequent P4 quantitation (being the subject of further work). Optimisation of the immunoassay involved utilising two formats at both gold macro and SPEs with firstly PATC and secondly anti-P4 antibodies as innermost adsorbed layer. Both approaches involved incubation in BSA blocking agent and comparative data at a control thiol molecule verified selectivity of the surface for PATC. Ongoing work in our group involves (a) amplification of the redox signal for surface bound PATC with the assistance of Au nanoparticle signalling and optimisation of P4 quantitation in competitive assay format under immunoassay conditions, thus paving the way for new progesterone immunosensing opportunities with advantages of direct signalling and minimal time to result.

\section{Declaration of competing interest}

The authors declare that they have no known competing financial interests or personal relationships that could have appeared to influence the work reported in this paper.

\section{CRediT authorship contribution statement}

Jessica Kelch: Data curation, Formal analysis, Investigation, Writing - review \& editing. Aoife Delaney: Methodology, Formal analysis, Investigation. Fintan Kelleher: Data curation, Methodology, Writing - review \& editing. Priscilla Baker: Funding acquisition, Project administration, Investigation. Emmanuel Iwuoha: Funding acquisition, Project administration, Investigation. Eithne Dempsey: Conceptualization, Data curation, Formal analysis, Funding acquisition, Project administration, Writing - review \& editing.

\section{Acknowledgements}

The authors would like to acknowledge funding under the Science Foundation Ireland Investigator Programme 12/IP/1275, and mobility funding under Marie Curie Actions - International Research Staff Exchange GA318053.

\section{Appendix A. Supplementary data}

Supplementary data to this article can be found online at https://doi. org/10.1016/j.bios.2019.111876.

\section{References}

Aggarwal, N., Aggarwal, R., Mishra, P., Jain, J., Bansal, S., Jha, K., 2008. Design and evaluation of semicarbazones and thiosemicarbazones as novel anticonvulsants. Cent. Nerv. Syst. Agents Med. Chem. 8, 26-28. https://doi.org/10.2174/ 187152408783790596.

Arévalo, F.J., Messina, G.A., Molina, P.G., Zón, M.A., Raba, J., Fernández, H., 2010. Determination of progesterone (P4) from bovine serum samples using a microfluidic immunosensor system. Talanta 80. https://doi.org/10.1016/j.talanta.2009.10.059, 1986-92.

Balhara, A.K., Gupta, M., Singh, S., Mohanty, A.K., Singh, I., 2013. Early pregnancy diagnosis in bovines: current status and future directions. Sci. World J. 2013 https:// doi.org/10.1155/2013/958540.

Biot, C., Pradines, B., Sergeant, M.-H., Gut, J., Rosenthal, P.J., Chibale, K., 2007. Design, synthesis, and antimalarial activity of structural chimeras of thiosemicarbazone and ferroquine analogues. Bioorg. Med. Chem. Lett 17, 6434-6438. https://doi.org/ 10.1016/j.bmcl.2007.10.003.

Carralero, V., González-Cortés, A., Yáñez-Sedeño, P., Pingarrón, J.M., 2007. Development of a progesterone immunosensor based on a colloidal gold-graphiteTeflon composite electrode. Electroanalysis 19, 853-858. https://doi.org/10.1002/ elan.200603794.

Carralero, V., González-Cortés, A., Yáñez-Sedeño, P., Pingarrón, J.M., 2007. Nanostructured progesterone immunosensor using a tyrosinase-colloidal goldgraphite-Teflon biosensor as amperometric transducer. Anal. Chim. Acta 596, 86-91. https://doi.org/10.1016/j.aca.2007.05.046.

Dong, X.-X., Yuan, L.-P., Liu, Y.-X., Wu, M.-F., Liu, B., Sun, Y.-M., Shen, Y.-D., Xu, Z.-L., 2017. Development of a progesterone immunosensor based on thionine-graphene oxide composites platforms: improvement by biotin-streptavidin-amplified system. Talanta 170, 502-508. https://doi.org/10.1016/j.talanta.2017.04.054.

Du, G., Zhang, D., Xia, B., Xu, L., Wu, S., Zhan, S., Ni, X., Zhou, X., Wang, L., 2016. A label-free colorimetric progesterone aptasensor based on the aggregation of gold nanoparticles. Microchim. Acta 183, 2251-2258. https://doi.org/10.1007/s00604016-1861-0.

Fatondji, H.R., Kpoviessi, S., Gbaguidi, F., Bero, J., Hannaert, V., Quetin-Leclercq, J., Poupaert, J., Moudachirou, M., Accrombessi, G.C., 2013. Structure-activity relationship study of thiosemicarbazones on an African trypanosome: trypanosoma brucei brucei. Med. Chem. Res. 22, 2151-2162. https://doi.org/10.1007/s00044012-0208-6.

Glinma, B., Kpoviessi, S.D.S., Fatondji, R.H., Gbaguidi, F.A., Kapanda, C.N., Bero, J., Didier, M., Hannaert, V., Quetin-leclercq, J., Poupaert, J., Accrombessi, G.C., 2011. Synthesis, characterization and anti-trypanosomal activity of R- ( - ) carvone and arylketones-thiosemi carbazones and toxicity against Artemia salina, 01, 65-70. 
Jang, H., Ahmed, S.R., Neethirajan, S., 2017. GryphSens: a smartphone-based portable diagnostic reader for the rapid detection of progesterone in milk. Sensors 17 (1079). https://doi.org/10.3390/s17051079.

Khan, S.A., Asiri, A.M., Al-Amry, K., Malik, M.A., 2014. Synthesis, characterization, electrochemical studies, and in vitro antibacterial activity of novel thiosemicarbazone and its $\mathrm{Cu}(\mathrm{II}), \mathrm{Ni}(\mathrm{II})$, and Co(II) complexes. Sci. Wor. J. 2014 (592375) https://doi.org/10.1155/2014/592375.

Kissinger, P.T., Heineman, W.R., 1996. Laboratory Techniques in Electroanalytical Chemistry. Marcel Dekker, Inc.

Mondal, M., Rajkhowa, C., Prakash, B.S., 2006. Relationship of plasma estradiol-17beta, total estrogen, and progesterone to estrus behavior in mithun (Bos frontalis) cows. Horm. Behav. 49, 626-633. https://doi.org/10.1016/j.yhbeh.2005.12.015.

Monerris, M.J., Arévalo, F.J., Fernández, H., Zon, M.A., Molina, P.G., 2012. Integrated electrochemical immunosensor with gold nanoparticles for the determination of progesterone. Sensors Actuators. Biol. Chem. 166-167, 586-592. https://doi.org/ 10.1016/j.snb.2012.03.015.

Murugkar, A., Unnikrishnan, B., Padhye, S., Bhonde, R., Teat, S., Triantafillou, E., Sinn, E., 1999. Hormone anchored metal complexes. 1. Synthesis, structure, spectroscopy and in vitro antitumor activity of testosterone acetate thiosemicarbazone and its metal complexes. Met. Based. Drugs 6, 177-182. https:// doi.org/10.1155/MBD.1999.177.

Oku, Y., Osawa, T., Hirata, T.-I., Kon, N., Akasaka, S., Senosy, W.S., Takahashi, T., Izaike, Y., 2011. Validation of a direct time-resolved fluoroimmunoassay for progesterone in milk from dairy and beef cows. Vet. J. 190, 244-248. https://doi. org/10.1016/j.tvjl.2010.10.024.

Pahontu, E., Julea, F., Rosu, T., Purcarea, V., Chumakov, Y., Petrenco, P., Gulea, A., 2015. Antibacterial, antifungal and in vitro antileukaemia activity of metal complexes with thiosemicarbazones. J. Cell Mol. Med. 19, 865-878. https://doi.org/ 10.1111/jcmm.12508.

Randivvir, E.P., Banks, C.E., 2013. Electrochemical impedance spectroscopy; an overview of bioanalytical applications. Anal. Methods 5, 1098-1115.

Trapiella-Alfonso, L., Costa-Fernández, J.M., Pereiro, R., Sanz-Medel, A., 2011. Development of a quantum dot-based fluorescent immunoassay for progesterone determination in bovine milk. Biosens. Bioelectron. 26, 4753-4759. https://doi.org/ 10.1016/j.bios.2011.05.044 